\title{
Current Knowledge of Breastfeeding Among Health Workers in a Developing Country Setting: A Survey in Calabar, Nigeria
}

Joanah M. Ikobah ${ }^{1}$, Offiong Ikpeme ${ }^{2}$, Ogban Omoronyia ${ }^{3}$, Nnette Ekpenyong ${ }^{3}$, Ekong Udoh ${ }^{4}$

1. Hepatology and Nutrition Division, Department of Paediatrics, University of Calabar/University of Calabar Teaching Hospital, Calabar, NGA 2. Department of Paediatrics, University of Calabar/University of Calabar Teaching Hospital, Calabar, NGA 3. Department of Community Medicine, University of Calabar/University of Calabar Teaching Hospital, Calabar, NGA 4. Department of Paediatrics, University of Uyo/University of Uyo Teaching Hospital, Uyo, NGA

Corresponding author: Joanah M. Ikobah, ikobah.joan@gmail.com

\section{Abstract \\ Background}

Health workers are in a strategic position to provide correct information to mothers on breastfeeding practice. This study assessed knowledge of breastfeeding among health workers in health facilities in Calabar.

\section{Methods}

This was a cross-sectional descriptive study. A 45-item self-administered questionnaire was used to obtain data. Ethical clearance for the study was obtained from the Cross River State Research and Ethics Committee. Data were analyzed using SPSS version 21.0 (SPSS, Inc., Chicago, USA). A knowledge score of at least $90 \%$ was considered satisfactory. Factors associated with the level of knowledge were determined using chi-square. The p-value was set at 0.05 .

\section{Result}

Two hundred and twenty-five healthcare professionals were surveyed, with a mean age of $37.5 \pm 9.4$ years, ranging from 20 to 65 years. The commonest age group was 41 to 50 years (43.1\%). Females (80.9\%) formed a larger proportion of participants with a female-male ratio of $4: 1$. The mean percentage of knowledge score was $85.1 \pm 9.0 \%$. A satisfactory level of knowledge was found in $27.1 \%$ of respondents. About one-third (33.7\%) and one-fifth (21.8\%) of health workers were not aware of the weight control benefit and protection against osteoporosis of breastmilk, respectively. Approximately one-fifth (22.2\%) of respondents had misconceptions concerning the effects of colostrum on the prevention of neonatal jaundice. Nurses with diploma level of training had a satisfactory level of knowledge, compared with other professions $(p<0.05)$.

Received 08/24/2020

Review began 08/28/2020 Review ended 09/09/2020 Published 09/15/2020

(c) Copyright 2020

Ikobah et al. This is an open access article distributed under the terms of the Creative Commons Attribution License CC-BY 4.0., which permits unrestricted use, distribution, and reproduction in any medium, provided the original author and source are credited.

\section{Conclusion}

Health workers' knowledge of breastfeeding was generally good though suboptimal. Health-related professions should provide current information on the best breastfeeding practices.

Categories: Pediatrics, Public Health

Keywords: breastfeeding, health workers, knowledge, child survival, nigeria

\section{Introduction}

Breastfeeding is a public health strategy for improving infant morbidity and mortality [1]. Exclusive breastfeeding decreases the risk of mortality from diarrhea and pneumonia [2]. It supports the immune system of the infant and could protect from later life non-communicable diseases such as diabetes and obesity [2]. The World Health Organization (WHO) and United Nations Children's Fund (UNICEF) recommends that every infant be exclusively breastfed for the first six months of life, with breastfeeding continuing for up to two years of age [3]. The UNICEF 2019 global databases show that only $44 \%$ of newborns are commenced on breastmilk within one hour of delivery and about $40 \%$ of infants are exclusively breastfed in the first six months of life [2].

The exclusive breastfeeding rate for children under six months in Nigeria is $29 \%$ following the 2018 Nigeria Demographic Health Survey (NDHS) with the average duration of exclusive breastfeeding in Nigeria being 2.8 months [4]. This is the highest in Nigeria in the last decade from 2008 to 2018, where the rate was $13 \%$ in 2008 and $17 \%$ in $2013 \%[4,5]$.

There are many factors contributing to the unacceptable low rates of breastfeeding globally [6-8]. One of the 
factors is the role of health workers. Health workers play a key role in supporting the initiation and establishment of effective breastfeeding of neonates by their mothers. Health workers are in a strategic position and have the responsibility to educate and counsel mothers and the general public towards proper initiation and adherence to recommended infant feeding practices [6-8]. Health workers are expected to have at least sufficient knowledge of various aspects of breastfeeding, including its benefits, proper techniques, existing myths, and practical aspects of managing potential challenges. Inadequate support by health workers towards positive breastfeeding practices has been reported in the past $[9,10]$. Okolo and Ogbonna working in Keffi, Nigeria showed that there was poor awareness of health workers in promoting and sustaining breastfeeding [11]. In a study carried out in Ikom, South-South Nigeria, about one-third of the health workers could not name more than two components of breast milk and $75.1 \%$ failed to identify more than three advantages of breastfeeding [12]. Improved healthcare practices stand out as being the most promising means of reinforcing the prevalence and duration of breastfeeding [10].

The majority of nursing mothers are largely dependent on health workers for acquisition and improvement in their knowledge of breastfeeding [12].

Health workers are an important source of support for breastfeeding mothers and their knowledge can influence a mothers' decisions to initiate and continue breastfeeding. There is a dearth study on the knowledge of healthcare professionals on breastfeeding in Cross River State hence this study. Findings from this study will be used in developing appropriate strategies to promote breastfeeding practices in Cross River State and Nigeria as a whole.

\section{Materials And Methods \\ Study area}

The study was conducted in Calabar, the capital city of Cross River State, in the south-south geo-political zone of Nigeria.

\section{Study design}

This was a cross-sectional study.

\section{Study population}

The study participants comprised of nurses, medical doctors, community health workers, pharmacists, and physiotherapists. Participants were attendees at a nutrition workshop in Calabar drawn from primary health centers, private hospitals, secondary health facilities, and tertiary health facilities in Calabar.

\section{Sample size estimation}

The formula for single proportion [13] $\mathrm{n}=\mathrm{z} 2 \mathrm{pq} / \mathrm{d} 2$ was used to calculate sample size in this study, where $\mathrm{n}$ was the sample size, " $z$ " critical value set at $95 \%$ alpha level of significance (1.96), "d" was estimated margin of error (0.05), "p" was estimated proportion of health workers with adequate knowledge of exclusive breastfeeding (0.84) as reported in the previous study [14] and $q=1-p=0.16$. With the assumption of a $5 \%$ non-response rate, this yielded a minimum sample size of 217 .

\section{Sampling technique}

Attendees were recruited to participate in the workshop and the study from their different health institutions (place of practice) in Calabar, using a systematic random sampling technique, with registers obtained from the Cross River State Ministry of Health as the respective sampling frames. Each sampling interval (k) was calculated by dividing the number of relevant staff in the different institutions (using available registers) by the proportionately allocated sample size for that institution. Hence, sampling intervals k of 5, 3, 3, 4, 2 was estimated for tertiary (622/122), general (57/19), private (127/39) hospitals, and primary health care (86/23) and other (47/22) centers, respectively. Subjects were recruited by balloting between the first participant and the kth participant on the respective registers. Thereafter, subsequent subjects were recruited using the estimated sampling interval for the different institutions. If a subject did not consent to participate, the next staff on the register was selected and sampling continued from that point. Sampling was carried out until the estimated sample size was completed.

\section{Data collection}

A 45-item self-administered semi-structured questionnaire assessing different aspects of breastfeeding was used to obtain data from consenting participants. The questionnaire consisted of demographic data of the participants and breastfeeding knowledge: benefits to babies, benefits to mothers, colostrum, effective feeding, timing and duration of breastfeeding and complementary feeding, common breastfeeding problems, and practical aspects of breastfeeding.

\section{Ethical issues}




\section{Cureus}

Ethical clearance for the study was obtained from the Cross River State Research and Ethics Committee. The confidentiality of the participants was preserved by the use of identification numbers

\section{Statistical analysis}

Data were analyzed using Statistical Package for Social Sciences (SPSS version 21.0, Chicago, Inc., USA). The participant's characteristics were described using frequency and percentage for categorical variables and means for continuous variables. The sum of correct responses was determined for each respondent. A knowledge score of $\geqslant 90 \%$ was classified as Good, 50-89\% classified as Fair while < 50\% was classified as Poor. The knowledge score was further classified as satisfactory if $\geqslant 90 \%$ or unsatisfactory if $<90 \%$. Pearson's chisquare test was used to determine the association between the socio-demographic variables of the participants and their knowledge of breastfeeding. The test was deemed significant at $\mathrm{p}$-value $<0.05$.

\section{Results}

\section{Socio-demographics of participants}

Two hundred and twenty-five healthcare professionals including medical doctors, nurses, community health workers, and others were surveyed, with a mean age of $37.5 \pm 9.4$ years, ranging from 20 to 65 years. The commonest age group was 41 to 50 years (43.1\%). Most subjects were females (80.9\%), married (59.6\%), nurses $(60.0 \%)$, practiced in a tertiary hospital (54.2\%), and have had 10 or less years of practice experience (57.8\%; Table 1). 


\section{Cureus}

\begin{tabular}{|c|c|c|}
\hline Variable & Frequency & Percentage \\
\hline \multicolumn{3}{|l|}{ Age group (years) } \\
\hline$<30$ & 57 & 25.3 \\
\hline $31-40$ & 97 & 43.1 \\
\hline $41-50$ & 39 & 17.3 \\
\hline$>50$ & 32 & 14.2 \\
\hline Total & 225 & 100 \\
\hline \multicolumn{3}{|l|}{ Gender } \\
\hline Male & 43 & 19.1 \\
\hline Female & 182 & 80.9 \\
\hline Total & 225 & 100 \\
\hline \multicolumn{3}{|l|}{ Marital status } \\
\hline Married & 134 & 59.6 \\
\hline Single & 83 & 36.9 \\
\hline Widowed & 6 & 2.7 \\
\hline Divorced/separated & 2 & 0.9 \\
\hline Total & 225 & 100 \\
\hline \multicolumn{3}{|c|}{ Highest professional qualification } \\
\hline Diploma & 134 & 59.6 \\
\hline First degree & 63 & 28 \\
\hline Certificate & 22 & 9.8 \\
\hline Second degree & 6 & 2.7 \\
\hline Total & 225 & 100 \\
\hline \multicolumn{3}{|l|}{ Place of practice } \\
\hline Tertiary hospital & 122 & 54.2 \\
\hline Private hospital & 39 & 17.3 \\
\hline PHC & 23 & 10.2 \\
\hline General hospital & 19 & 8.4 \\
\hline Others & 22 & 9.8 \\
\hline Total & 225 & 100 \\
\hline \multicolumn{3}{|c|}{ Duration of practice (in years) } \\
\hline 10 or less & 130 & 57.8 \\
\hline $11-20$ & 51 & 22.7 \\
\hline $21-30$ & 34 & 15.1 \\
\hline$>30$ & 10 & 4.4 \\
\hline Total & 225 & 100 \\
\hline
\end{tabular}

TABLE 1: Sociodemographic characteristics of respondents $(\mathrm{N}=\mathbf{2 2 5})$ 


\section{Cureus}

Table 2 shows frequency distribution of correct and incorrect responses of participants to the knowledge of benefits and principles of breastfeeding. Most subjects knew the benefits of breastfeeding to babies and mothers, except for knowledge items 9 and 11, where approximately one-third (33.7\%) and one-fifth (21.8\%) did not know of the weight control benefit and protection against osteoporosis, respectively. Approximately one-fifth (22.2\%) of respondents had misconception concerning effects of colostrum on prevention of neonatal jaundice (item 16).

\begin{tabular}{|c|c|c|c|}
\hline \multirow{2}{*}{ S/N } & \multirow{2}{*}{ Breastfeeding Knowledge Item } & Correct & Incorrect \\
\hline & & n (\%) & $\mathrm{n}(\%)$ \\
\hline \multicolumn{4}{|c|}{ Benefits to babies } \\
\hline 1 & Breastfeeding reduces the risk of respiratory infection among babies & $219(97.3)$ & $6(2.7)$ \\
\hline 2 & Breastfeeding increases the baby's intelligence & $216(96.0)$ & $9(4.0)$ \\
\hline 3 & Breastfeeding helps to reduce the incidence of child abuse and neglect & 219 (97.3) & $6(2.7)$ \\
\hline 4 & Baby who received breastfeeding is less prone to get diarrhea & $215(95.6)$ & $10(4.4)$ \\
\hline 5 & Breast milk provides baby with more protection from allergy compared to formula milk & $221(98.2)$ & $4(1.8)$ \\
\hline 6 & Breastfeeding causes good development of baby's teeth and gum & $211(93.8)$ & $14(6.2)$ \\
\hline \multicolumn{4}{|c|}{ Benefits to mothers } \\
\hline 7 & Exclusive breastfeeding is beneficial in spacing birth & $217(96.4)$ & $8(3.6)$ \\
\hline 8 & Breastfeeding helps to stimulate uterine contraction & 214 (95.1) & $11(4.9)$ \\
\hline 9 & Mothers who practiced breastfeeding may achieve pre-pregnancy weight faster & $138(61.3)$ & $87(33.7)$ \\
\hline 10 & Frequent breastfeeding may prevent breast engorgement & $201(89.3)$ & $24(10.7)$ \\
\hline 11 & Mother who practiced breastfeeding has a low risk of getting breast cancer & $212(94.2)$ & $13(5.8)$ \\
\hline 12 & Breastfeeding may protect against osteoporosis & 176 (78.2) & $49(21.8)$ \\
\hline \multicolumn{4}{|c|}{ Colostrum } \\
\hline 13 & Colostrum is the mother's early milk, which is thick, sticky, and yellowish & $216(96.0)$ & $9(4.0)$ \\
\hline 14 & Colostrum is difficult to digest and needs to be discarded & 217 (96.4) & $8(3.6)$ \\
\hline 15 & Colostrum causes constipation among babies & $211(93.8)$ & $14(6.2)$ \\
\hline 16 & Colostrum is not able to protect babies from jaundice & $175(77.8)$ & $50(22.2)$ \\
\hline \multicolumn{4}{|c|}{ Effective feeding } \\
\hline 17 & Babies will gain weight if they receive effective feeding & 210 (93.3) & $15(6.7)$ \\
\hline 18 & Correct positioning helps to achieve effective breastfeeding & $221(98.2)$ & $4(1.8)$ \\
\hline 19 & Babies sleep well after they receive adequate breastfeeding & $223(99.1)$ & $2(0.9)$ \\
\hline \multicolumn{4}{|c|}{ Timing and duration of breastfeeding and complementary feeding } \\
\hline 20 & Breastfeeding should be initiated within 30 minutes after delivery & $216(96.0)$ & $9(4.0)$ \\
\hline 21 & Breastfeeding should be given on demand & $207(92.0)$ & $18(8.0)$ \\
\hline 22 & Baby should be allowed to breastfeed for at least $10-20$ minutes per session & $210(93.3)$ & $15(6.7)$ \\
\hline 23 & Breastfeeding should be continued up to two years even though the baby has received complementary food & $210(93.3)$ & $15(6.7)$ \\
\hline 24 & Complementary feeding should be introduced at six months of age & $215(95.6)$ & $10(4.4)$ \\
\hline 25 & Mothers may mix breastfeeding and formula feeding once the baby start & $201(89.3)$ & 24 \\
\hline
\end{tabular}

TABLE 2: Frequency distribution of knowledge of breastfeeding benefits and principles $(N=225)$ 


\section{Cureus}

Table 3 shows frequency distribution of correct responses to knowledge of problems and practical aspects of breastfeeding. Incorrect responses were provided by $51.1 \%, 24.0 \%, 24.9 \%$, and $36.0 \%$ of respondents concerning the effects of inverted nipple (item 27), appropriate response to cracked nipple (item 28), and breast engorgement (items 30 and 31), respectively. Commonly misconceived practical aspects of breastfeeding included breast milk freeze storage (item 39, 67.1\%), effect of massage during breast engorgement (item 33, 37.3\%), regularity of breast milk expression (item 38, 33.8\%), and refrigeration of breast milk (item $40,32.0 \%$ ).

\begin{tabular}{|c|c|c|c|}
\hline \multirow{2}{*}{$\mathbf{S} / \mathbf{N}$} & \multirow{2}{*}{ Breastfeeding Knowledge Item } & Correct & Incorrect \\
\hline & & $\mathrm{n}(\%)$ & $n(\%)$ \\
\hline \multicolumn{4}{|c|}{ Common breastfeeding problems } \\
\hline 26 & Breast milk production is influenced by breast size & $202(89.8)$ & $23(10.2)$ \\
\hline 27 & Mothers with inverted nipples cannot breastfeed their babies & $110(48.9)$ & $115(51.1)$ \\
\hline 28 & Breastfeeding must be discontinued if the mother has a cracked nipple & $171(76.0)$ & $54(24.0)$ \\
\hline 29 & Breastfeeding must be discontinued if the baby has jaundice & $198(88.0)$ & $27(12.0)$ \\
\hline 30 & Breastfeeding must be discontinued if the mother has breast engorgement & $169(75.1)$ & $56(24.9)$ \\
\hline 31 & Breast engorgement may be reduced with cold packs & $144(64.0)$ & $81(36.0)$ \\
\hline \multicolumn{4}{|c|}{ Practical aspects } \\
\hline 32 & Exclusive breastfeeding must be practiced until the infant is 6 months old & $213(94.7)$ & $12(5.3)$ \\
\hline 33 & Massage may reduce breast engorgement & $141(62.7)$ & $84(37.3)$ \\
\hline 34 & Giving water to the baby is encouraged after every breastfeeding & $197(87.6)$ & $28(12.4)$ \\
\hline 35 & Belching after feeding shows that the baby is full & $167(74.2)$ & $58(25.8)$ \\
\hline 36 & Babies who get enough feeding will pass urine more frequently & 177 (78.7) & $48(21.3)$ \\
\hline 37 & Oral thrush frequently happens to babies who breastfeed & 176 (78.2) & $49(21.8)$ \\
\hline 38 & Breast milk expression may be done every three hours & $149(66.2)$ & 76 (33.8) \\
\hline 39 & Expressed breast milk may be stored for three months in a freezer & $74(32.9)$ & $151(67.1)$ \\
\hline 40 & Expressed breast milk may be stored for $24-48$ hours in a refrigerator & $153(68.0)$ & $72(32.0)$ \\
\hline 41 & It is necessary to express breast milk from one side of the breast only & $207(92.0)$ & $18(8.0)$ \\
\hline 42 & Expressed breast milk may be mixed with previously expressed milk & $183(81.3)$ & $42(18.7)$ \\
\hline 43 & Expressed breast milk may be warmed on a fire & $194(86.2)$ & 31 (13.8) \\
\hline 44 & Expressed breast milk may be warmed in a microwave & $182(80.9)$ & $43(19.1)$ \\
\hline 45 & The leftover expressed breast milk that has been used & 164 (72.9) & $61(27.1)$ \\
\hline
\end{tabular}

TABLE 3: Frequency distribution of knowledge of breastfeeding problems and practice $(N=225)$

\section{Overall knowledge score of participants on breastfeeding practice}

The mean score on knowledge of breastfeeding was $40.0 \pm 4.2$, ranging from $13.0 \%$ to $45.0 \%$. This corresponded to mean percentage score of $85.1 \pm 9.0 \%$, ranging from $27.7 \%$ to $100 \%$.

Table 4 shows frequency distribution of categories of level of knowledge of breastfeeding determined from the percentage knowledge scores. Most respondents 163 (72.5\%) had not satisfactory (fair) knowledge of breastfeeding practice while 61(27.1\%) had satisfactory (good) knowledge of breastfeeding. 


\section{Cureus}

Variable

Frequency

Percentage

Sub-categories of knowledge level

Poor $(<50)$

Fair (50-89)

Satisfactory (>90)

Total

Main-categories of knowledge level

Not satisfactory $(<90)$

Satisfactory $(>90)$

Total
1

163

61

225

164

61

225
0.4

27.1

100

72.9

27.1

100

TABLE 4: Frequency distribution of knowledge of breastfeeding categories $(\mathrm{N}=225)$

Not satisfactory $=$ sum of poor and fair knowledge. Satisfactory $=$ good knowledge.

Table 5 shows relationship between socio-demographic and occupational factors and level of knowledge of breastfeeding. Significantly higher proportion of nurses with diploma level of training had satisfactory level of knowledge, compared with other professions $(\mathrm{p}<0.05)$. Other variables were not found to significantly influence level of knowledge of breastfeeding $(\mathrm{p}>0.05)$. 


\section{Cureus}

\begin{tabular}{|c|c|c|c|c|}
\hline \multirow{3}{*}{ Variable } & \multicolumn{2}{|c|}{ Breastfeeding Knowledge Category } & \multirow{2}{*}{ Total } & \multirow{3}{*}{ Chi-Square (p-Value) } \\
\hline & Not satisfactory & Satisfactory & & \\
\hline & $n(\%)$ & $n(\%)$ & $n(100)$ & \\
\hline \multicolumn{5}{|l|}{ Age groups (in years) } \\
\hline$<30$ & $35(61.4)$ & $22(38.6)$ & $57(100)$ & 5.9 \\
\hline $31-40$ & 72 (74.2) & $25(25.8)$ & $97(100)$ & $(0.12)$ \\
\hline $41-50$ & $31(79.5)$ & $8(20.5)$ & $39(100)$ & \\
\hline$>50$ & 26 (81.2) & $6(18.8)$ & $32(100)$ & \\
\hline Total & 164 (72.9) & $61(27.1)$ & $225(100)$ & \\
\hline \multicolumn{5}{|l|}{ Gender } \\
\hline Male & $29(67.4)$ & $14(32.6)$ & $43(100)$ & 2.8 \\
\hline Female & 97 (53.3) & $85(46.7)$ & $182(100)$ & $(0.09)$ \\
\hline Total & $126(56.0)$ & $99(44.0)$ & 225 (100) & \\
\hline \multicolumn{5}{|l|}{ Level of training } \\
\hline Certificate & 20 (90.9) & $2(9.1)$ & $22(100)$ & Fisher's \\
\hline Diploma (in nursing) & $87(64.9)$ & $47(35.1)$ & $134(100)$ & Exact \\
\hline First degree & $52(82.5)$ & $11(17.5)$ & $63(100)$ & $(0.01)$ \\
\hline Second degree & $5(83.3)$ & $1(16.7)$ & $6(100)$ & \\
\hline Total & $164(72.9)$ & $61(27.1)$ & $225(100)$ & \\
\hline \multicolumn{5}{|c|}{ Duration of practice (years) } \\
\hline$<10$ & 87 (66.9) & $43(33.3)$ & $130(100)$ & Fisher's \\
\hline 11-20. & 39 (76.5) & $12(23.5)$ & $51(100)$ & Exact \\
\hline $21-30$ & 30 (88.2) & $4(11.8)$ & $34(100)$ & $(0.07)$ \\
\hline$>30$ & $8(80.0)$ & $2(20.0)$ & $10(100)$ & \\
\hline tal & $44(72.9)$ & $61(27.1)$ & (100) & \\
\hline
\end{tabular}

TABLE 5: Factors associated with knowledge of breastfeeding category $(\mathrm{N}=225)$

\section{Discussion}

The overall knowledge of health workers on breastfeeding practices in this study was $85.1 \pm 9.0 \%$ which was below the cut-off of $90.0 \%$ for satisfactory knowledge. Satisfactory knowledge of breastfeeding practices was observed in $27.1 \%$ of the respondent. This is, however, lower than that observed by Utoo et al. working in the sub-urban city of Ikom [12]. The paucity of knowledge on breastfeeding practices among health workers in the index study raises concerns about the quality of health talks and counselling offered to mothers and other caregivers of young infants in health facilities.

Knowledge of health workers on the benefits of breastfeeding to babies, their mothers, colostrum, effective breastfeeding, timing, and duration of exclusive breastfeeding and complementary feeding was good. However, their knowledge was suboptimal regarding the effect of breastfeeding on the achievement of prepregnancy weight, protection against osteoporosis, and colostrum in the protection of babies from jaundice. In a survey conducted in Tanzania, 97\% of health workers stated a lack of knowledge of the benefits of exclusive breastfeeding as one of the main reasons for the low breastfeeding rate [15]. A majority of the general public including nursing mothers largely depend on health workers for acquisition and improvement of their knowledge of breastfeeding [12].

Most of the respondents had satisfactory knowledge of the importance of colostrum. This is like that 
observed by Utoo et al., colostrum is known to have several immunologic properties that protect the baby against infections in early life [12]. Mothers are more likely to practice exclusive breastfeeding if they know the protective function of colostrum against several pathogenic gut organisms. However, $77.8 \%$ of health workers had poor knowledge about colostrum protecting babies from jaundice. This level of knowledge is highly unacceptable as jaundice is among the leading causes of neonatal morbidity and mortality in most developing countries [16].

About $96 \%$ of health workers knew that breastfeeding should be initiated within one hour after delivery. This finding suggests that women attended by these health workers were more likely to commence breastfeeding of their infant soon after delivery. This finding is similar to that obtained in a study among health workers in rural South Africa, which reported a knowledge rate of $96 \%$ among professional nurses [10], however, the study in Keffi, Nigeria reported a lower knowledge rate of $20 \%$ of initiation of breastfeeding within one hour after delivery [11].

Most of the respondents knew exclusive breastfeeding to be recommended for the first six months of life. This finding is similar to that obtained in Ikom, Nigeria among health workers [12]. This response of health workers if sustained and practiced by nursing mothers could improve the low exclusive breastfeeding rate in Nigeria.

Although, $12.4 \%$ of health workers believed that infants less than six months should be given water during exclusive breastfeeding. This is however lower than $19.2 \%$ and $15.7 \%$ that subscribed to the use of water alongside breastfeeding before six months of life by Okolo and Ogbonna [11] in Keffi, Nigeria and Sadoh et al. [17] among medical women in Benin City, Nigeria, respectively. This response by health workers may reflect the common cultural myth in Nigeria that breastfed babies are usually thirsty and would need to drink some water in order to be satisfied. Sachdev et al. [18] had demonstrated that fully breastfed babies in the tropics do not need water even in extremely hot dry climates.

Knowledge concerning common breastfeeding problems was generally not satisfactory. Good knowledge was reported in $10 \%$ of the questions used to assess the participants in this domain. About a quarter of the respondents believed that breastfeeding should be discontinued if mothers have cracked nipples or breast engorgement while about half of them believed mothers with inverted nipples cannot breastfeed their babies. The above-mentioned problems for which the health workers permitted discontinuation of breastfeeding are remediable challenges that should not obviate the practice of breastfeeding. Reasons similar to the findings in this study were attributed to the premature discontinuation of breastfeeding in Keffi, Nigeria [11] and by Chale et al. [15] in Tanzania, East Africa. This may suggest that health workers in these settings will not promote breastfeeding among mothers with those conditions. Borbala [6] and Robertson [8] have shown that poor knowledge of breastfeeding among health workers impair effective breastfeeding practices.

The age of the health workers, gender, and years of practice were not significantly associated with satisfactory knowledge of breastfeeding in this study. Chale et al. in Tanzania [15] demonstrated that years of practice, age, and gender were not significantly associated with good knowledge of breastfeeding among health workers.

There was a significant association between the cadre of health staff and knowledge of breastfeeding in this study. The knowledge of breastfeeding practice was significantly higher among those with a diploma in nursing compared with other health professionals. Medical doctors had inadequate knowledge of breastfeeding compared to nurses. The observation in this study is quite understandable since most of the health education to caregivers in health facilities is performed by nurses. The finding in this study is however contrary to the report of Chale et al. [15] and Okolo and Ogbonna [11] who reported better knowledge of breastfeeding practices among medical doctors and a higher likelihood of clinicians encouraging the practice of exclusive breastfeeding compared to other health workers.

A limitation of this study is the skewness in favour of nurses in the selection of participants This bias in the selection of respondents might have influenced some of the findings of this study, though most of the respondents were from the tertiary health facility with a representative from more than ten states of Nigeria and the neighbouring Republic of Cameroun.

\section{Conclusions}

The overall knowledge of health workers on breastfeeding practices was suboptimal. Health workers had good knowledge of the benefits of breastfeeding and breastfeeding practices but their knowledge of common problems of breastfeeding and practical steps on breastfeeding was quite low. Training and re-training of all health workers in the State on the importance of breastfeeding are necessary to improve their knowledge of breastfeeding practice.

\section{Additional Information}




\section{Disclosures}

Human subjects: Consent was obtained by all participants in this study. Cross River State Health Research Ethics Committee issued approval CRSMOH/RP/REC/2020/126. Animal subjects: All authors have confirmed that this study did not involve animal subjects or tissue. Conflicts of interest: In compliance with the ICMJE uniform disclosure form, all authors declare the following: Payment/services info: All authors have declared that no financial support was received from any organization for the submitted work. Financial relationships: All authors have declared that they have no financial relationships at present or within the previous three years with any organizations that might have an interest in the submitted work. Other relationships: All authors have declared that there are no other relationships or activities that could appear to have influenced the submitted work.

\section{References}

1. James DC, Lessen R, American Dietetic Association: Promoting and supporting breastfeeding. J Am Diet Assoc. 2009, 109:1926-1942. 10.1016/j.jada.2009.09.018

2. UNICEF global databases, 2019 based on MICS, DHS and other nationally representative sources . (2019). Accessed: September 15, 2020: http://www.data.unicef.org.

3. Global strategy for infant and young child feeding . (2003). Accessed: September 15, 2020: https://www.who.int/nutrition/topics/global_strategy/en/.

4. Nigeria Demographic and Health Survey 2018 . (2018). Accessed: April 20, 2020: http://www.dhsprogram.com/pubs/pdf/SR264/SR264.pdf.

5. Nigeria Demographic and Health Survey 2013 . (2014). Accessed: September 15, 2020: https://www.unicef.org/nigeria/reports/nigeria-demographic-and-health-survey-2013.

6. Borbala A: Hungaria hospital's best medicine for sick and high-risk babies . BFHI News, 1994.

7. Brown A, Raynor P, Lee M: Healthcare professionals' and mothers' perceptions of factors that influence decisions to breastfeed or formula feed infants: a comparative study. J Adv Nurs. 2011, 67:1993-2003. 10.1111/j.1365-2648.2011.05647.x

8. Robertson A: UN Agencies joins to protect breastfeeding in ex-Yugoslavia . BFHI News, 1994.

9. Popkin BM, Canahuati J, Bailey PE, O'Gara C: An evaluation of a national breastfeeding promotion programme in Honduras. J Biosoc Sci. 1991, 23:5-21. 10.1017/S0021932000019027

10. Shah S, Rollins NC, Bland R: Breastfeeding knowledge among health workers in rural South Africa . J Trop Pediatr. 2005, 51:33-38. 10.1093/tropej/fmh071

11. Okolo SN, Ogbonna C: Knowledge, attitude and practice of health workers in Keffi local government hospitals regarding baby-friendly hospital initiative (BFHI) practices. Eur J Clin Nutr. 2002, 56:438-441. 10.1038/sj.ejcn.1601331

12. Utoo BT, Ochejele S, Obulu MA, Utoo PM: Breastfeeding knowledge and attitude among Health Workers in a Health Care Facility in South-South Nigeria: the need for middle level health manpower development. Clin Mother Child Health. 2012, 9:1-5. 10.4303/cmch/235565

13. Kish L: Survey sampling. Wiley-Interscience, New York; 1995.

14. Ella RE, Ndep AO, Akpan MI: Factors affecting exclusive breastfeeding practice in rural communities of Cross River State, Nigeria. Int J Hum Soc Sci Educ. 2016, 3:101-110. 10.20431/2349-0381.0304012

15. Chale L, Fenton T, Kayange N: Predictors of knowledge and practice of exclusive breastfeeding among health workers in Mwanza City, Northwest Tanzania. BMC Nurs. 2016, 15:2-8. 10.1186/s12912-016-0192-0

16. Olusanya BO, Osibanjo FB, Mabogunje CA, Slusher TM, Olowe SA: The burden and management of neonatal jaundice in Nigeria: a scoping review of the literature. Niger J Clin Pract. 2016, 19:1-17. 10.4103/11193077.173703

17. Sadoh AE, Sadoh WE, Oniyelu P: Breast feeding practice among medical women in Nigeria . Niger Med J. 2011, 52:7-12.

18. Sachdev HP, Krishna J, Puri RK, Satyanarayana L, Kumar S: Water supplementation in exclusively breastfed infants during summer in the tropics. Lancet. 1991, 337:929-933. 10.1016/0140-6736(91)91568-F 